Fecha de recepción: diciembre 2017 Fecha de aceptación: octubre 2018 Versión final: julio 2019

\section{Propiciar la multimodalidad en niños y adolescentes a través de la producción de humor gráfico}

Lucía Bugallo *, Constanza Zinkgräf ${ }^{\star 2}$ y

Ana Pedrazzini ${ }^{\star 3}$

\begin{abstract}
Resumen: Este trabajo busca aportar al estudio empíricamente fundado de la multimodalidad y el humor en niños y adolescentes. Focaliza en la producción de humor gráfico en tanto discurso multimodal, en el que diversos signos -en su mayoría icónicos, plásticos y lingüísticos- interactúan para producir sentido y crear un efecto humorístico. Tomando como corpus 134 viñetas humorísticas producidas por niñas/os y adolescentes de 10 a 19 años, analizamos las formas en que el dibujo y la escritura son puestos en relación y encontramos que la relación de complementariedad es la que prima, lo cual da cuenta de un esfuerzo por sacar provecho del potencial de cada modo semiótico. También identificamos el repertorio de recursos gráficos desplegados (con globos, líneas de movimiento, etiquetas y carteles como los más numerosos), atendiendo a usos con mayor o menor grado de convencionalidad e innovación y describimos diversas estrategias llevadas a cabo para producir viñetas inteligibles, relevando también dificultades sólo parcialmente superadas.
\end{abstract}

Palabras clave: humor - articulación multimodal - recursos gráficos - imagen.

[Resúmenes en inglés y portugués en las páginas 140-141]

(*) Lucía Bugallo es Lic. en Psicología (Universidad del Aconcagua) y doctoranda en la Universidad Nacional de La Plata. Ha trabajado como Asistente de investigación en el Instituto de Investigaciones de la Facultad de Psicología (UBA) y como Ayudante de Primera en la Práctica Profesional en Promoción de la Salud en Adolescentes (UBA). Actualmente, como becaria de CONICET, forma parte del Grupo Vinculado de Estudios Culturales y Cognitivos, del Instituto Patagónico de Estudios en Humanidades y Ciencias Sociales (IPEHCS-CONICET), en el cual desarrolla su Tesis Doctoral sobre la producción de humor gráfico en niños y adolescentes.

${ }^{\left({ }^{2}\right)}$ Constanza Zinkgräf, Licenciada en Psicología (UBA) y Magister en Educación, con especialización en las TIC en la Educación (Universidad de Jaén, España). Investigadora y profesora de la Universidad Nacional del Comahue, Facultad de Ciencias de la Educación. Profesora Adjunta Regular de Psicología Evolutiva, carrera de Servicio Social y Asistente de Docencia Regular de Psicología Genética y Psicología General de la carrera de Psicología. 
${ }^{\left({ }^{*}\right)}$ Ana Pedrazzini es Dra. en Ciencias de la Información y de la Comunicación (CELSAUniversidad Paris IV Sorbonne) y Dra. en Ciencias Sociales (Universidad de Buenos Aires). Es Investigadora Adjunta de CONICET en la Universidad Nacional del Comahue (ECyC/ IPEHCS: Grupo Vinculado de Estudios Culturales y Cognitivos, Instituto Patagónico de Estudios en Humanidades y Ciencias Sociales) en las áreas de comunicación, semiótica y retórica. Sus investigaciones versan fundamentalmente sobre la producción de humor gráfico en profesionales y niños.

\section{Introducción}

Si bien hoy en día existe amplio consenso entre educadores, investigadores y otros especialistas en el campo educativo en pensar la alfabetización desde una multiplicidad de modos semióticos -superando así el logocentrismo que primó durante siglos-, en numerosos planes de formación docente, planes curriculares y libros escolares subsiste la idea de que algunos de estos modos no requieren formación específica. Términos como los de "alfabetización visual" o su equivalente en inglés "picturacy", "graphicacy" (ver Bateman 2014: pp. 48-49) ponen de manifiesto la necesidad de enseñar a leer y producir imágenes (Avgerinou y Ericson, 1997; Unsworth, Thomas, Simpson y Asha, 2005; Pantaleo, 2005, 2014) desechando la falsa creencia de que la imagen es transparente y ampliando una concepción poco atenta al potencial de este modo semiótico en la que prima un uso meramente ilustrativo (Cruder, 2008). Su enseñanza, además, enriquece el uso de otros modos semióticos, como la oralidad y la escritura. La articulación entre la imagen y la escritura raramente abordada en los libros de textos y planes curriculares -al menos en la Argentina (Cruder 2008)-, reviste particular interés. Por un lado, conforma uno de los medios de comunicación más frecuentes (Martinec y Salway, 2005) y por lo tanto es necesario ser capaz de entender y desplegar gráficamente distintas formas de relación verbo-visuales. En este sentido, una comunicación eficaz exige el uso de combinaciones entre imagen y escritura que sean inteligibles (Bateman, 2014). Por otro lado, promueve habilidades de lectura de alto nivel que luego repercutirán en las producciones de los aprendices (Arizpe y Styles, 2003; Krusemark, 2016; Pantaleo, 2005).

Entre la diversidad de textos (Vilches, 1984) en los que la imagen y la escritura suelen articularse estrechamente y que resultan familiares en el mundo cotidiano de niños y adolescentes se encuentra el humor gráfico. En este género discursivo (Bajtín, 2003; Pedrazzini y Scheuer, 2018a; Steimberg, 1998), ambos modos semióticos se relacionan no sólo para producir sentido sino también para crear un efecto humorístico, es decir, una ruptura con lo previsible, instaurando así una incongruencia cuya resolución total o parcial puede producir disfrute (ver, entre otros, Attardo, 1994; Fourastié, 1983; Pedrazzini, 2015).

Si bien existen diversos antecedentes de uso de este género con fines pedagógicos, prima el foco puesto en su valor documental y argumentativo como disparador para abordar diversos contenidos (e.g. historia: Calvas-Ojeda y Espinoza Freire, 2017; física: Viau, Szigety y Tintori, 2015; matemática: León Gómez, 2013). La apuesta del presente trabajo es correr el 
foco de la interpretación a la producción. Sostenemos que producir humor gráfico es una actividad desafiante que exige y a la vez promueve un dominio medianamente sofisticado del dibujo y la escritura como modos de comunicación así como la capacidad de articularlos de forma eficaz e inteligible; jugar con sentidos propios y figurados; usar diversos recursos del género con fines comunicativos; entre otros. Buscamos así dar evidencia del potencial que su producción puede tener en el doble proceso de enseñanza y aprendizaje, siendo un medio fecundo a partir del cual los aprendices narran vivencias personales, expresan un punto de vista sobre algún aspecto de la realidad social, construyen una trama que los divierte (Bugallo, Zinkgräf y Pedrazzini, 2018).

\section{La multimodalidad en el humor gráfico}

El humor gráfico tiene a la imagen -y específicamente al dibujo- como principal modo semiótico, en el que signos icónicos y plásticos co-participan activamente en la producción de sentido (ver Grupo Mu, 1992; Joly, 2009). Muchas veces el dibujo se articula con la escritura, la cual ocupa un espacio variable, que puede extenderse desde un conjunto de fonemas a frases que funcionan como diálogos o voz del narrador. Tanto la imagen como la escritura se insertan en una viñeta, de formato generalmente cuadrado o rectangular. El humor gráfico puede ser de una única viñeta o bien puede estar compuesto de dos o más viñetas divididas por "calles". En este caso se habla de tira y al igual que la historieta, presenta una secuencia narrativa que se despliega espacial y temporalmente.

Diversos trabajos analizan la relación modal entre el dibujo y la escritura en el humor gráfico producido por profesionales (Samson y Huber, 2007; Tsakona, 2009; Pedrazzini y Scheuer, 2010, 2018), siendo un terreno poco explorado el del humor gráfico de niños y adolescentes. En sintonía con Kloepfer (1977, citado por Bateman, 2014) y más recientemente El Refaie (2013), Pedrazzini y Scheuer (2018b) distinguen dos tipos de relaciones básicas: de convergencia o de divergencia. En la convergencia, los modos verbal y visual aportan sentidos que confluyen en una o más ideas relacionadas. La relación es de complementariedad cuando la contribución es pareja, o bien un modo puede predominar sobre el otro. En el caso de la complementariedad, cada modo aporta información novedosa de relevancia para la producción de sentido y creación del efecto humorístico. Cuando hay predominio verbal, lo visual cumple un rol ilustrativo, mientras que cuando hay predominio visual, lo verbal o bien refuerza o amplía algún aspecto visual, o bien redunda parcialmente. Hablamos de redundancia parcial pues cada modo tiene su especificidad semiótica y no aporta lo mismo a la producción de sentido (Kress, 2010). En la divergencia, lo verbal y lo visual aportan sentidos que se contraponen en cierto grado, siendo esta contradicción deliberada y operando como un recurso para la generación de humor. Como señalan Pedrazzini y Scheuer, es necesario pensar estas categorías como un continuum con diversos matices y grados.

Además de la estrecha articulación de signos icónicos, plásticos y lingüísticos, en el humor gráfico pueden eventualmente intervenir otros modos semióticos como números, notas musicales o mapas. La multimodalidad se manifiesta también por vías más específicas, compartidas con un medio de comunicación muy próximo, la historieta (McCloud, 1994; 
Forceville, El Refaie y Meesters, 2014): la gestualidad es dibujada; los ruidos son escritos a través de onomatopeyas que se encuentran integradas visualmente en el relato; el movimiento es representado en la imagen fija a partir de líneas de movimiento; los diálogos entre los personajes, que remiten a la oralidad y son concebidos para ser escuchados más que para ser leídos, son escritos en globos cuya forma cambia según hablen, susurren o griten; e incluso se puede acceder al pensamiento de un personaje a partir de un globo específico. Para esto resulta clave contar con un bagaje que incluya formas convencionales de representar este entrecruzamiento modal.

Algunos autores advierten la dificultad de clasificar varios de estos recursos como inequívocamente visuales o lingüísticos (Saraceni, 2003; Kowalweski, 2015), como ha sido la tradición, y proponen en cambio considerarlos desde un continuum ("continuidad semiótica" para Kowalweski). Este enfoque parte de la definición de signo de Pierce (1998) en tanto construcción multifacética que muestra propiedades icónicas, indiciales y convencionales en proporciones variables aunque no necesariamente siempre co-presentes. Kowalweski argumenta su postura tomando el caso de la onomatopeya, el globo y la tipografía.

Las onomatopeyas son palabras que imitan sonidos (allí estaría su carácter a la vez indicial e icónico) y se representan mediante el sistema convencional de escritura, aunque con ciertos permisos ya que no se sujetan a la gramática y la ortografía. Los globos -como las onomatopeyas- intentan "capturar y hacer visible un elemento etéreo: el sonido" (Eisner, 1985: p. 26) y lo hacen a través de signos lingüísticos y plásticos. Tienen un fuerte componente indicial, dado por la posición respecto de los personajes y la cola del globo (Kowalweski, 2015). La forma del globo a su vez indica la prosodia. Por convención, el globo de habla se dibuja generalmente con una línea continua y recta; el globo de pensamiento y sueño, con líneas onduladas que conforman una nube; el globo de grito, con líneas en ángulo; el globo para indicar un susurro, con líneas discontinuas. La dirección de la "cola" del globo indica la procedencia del contenido, convencionalmente dibujada con una línea en ángulo, para los globos de habla, grito y susurro, y con esferas pequeñas en el caso del globo de pensamiento. Los globos contribuyen a construir la identidad del personaje y su estado emocional, así como la secuencia de interacción entre personajes (Cohn, 2013; Eisner, 1985; McCloud 1994; Yannicopoulou, 2004; Wallner, 2016). Si bien en general presentan en su interior signos verbales, en ocasiones articulan dibujos y palabras o bien sólo presentan dibujos.

Como hemos señalado, el tercer recurso que analiza Kowalewski para referirse a la continuidad modal o semiótica es la tipografía especial ("special lettering”: p. 7). Sin embargo, creemos que ésta no se encuentra en el mismo estatus que las onomatopeyas y los globos puesto que en realidad está presente en estos últimos y otros recursos multimodales. El carácter "especial” de la tipografía refiere a lo que autores como el Grupo Mu (1992) y Joly (2009) identifican como signos plásticos que se manifiestan en el trazo, el color, la textura, el tamaño, la disposición espacial, entre otros, y que operan en realidad en articulación con muchos signos: icónicos, numéricos, musicales, etc. Como indican los integrantes del Grupo Mu, lo plástico opera como signo pleno y autónomo.

Podríamos graficar esta "continuidad" o tal vez entrecruzamiento modal como sugerimos en la Figura 1, en la que ubicamos a la onomatopeya y al globo en la intersección de las propiedades icónica, indicial y convencional -el carácter icónico del globo opera 
fundamentalmente cuando hay dibujos en su interior. Otro recurso es el ideograma, que también reúne la triple condición icónica, indicial y convencional. Permite expresar vivencias, estados emocionales y/o sensaciones de los personajes así como también caracterizar situaciones. Muchos ideogramas son metáforas (propiedad icónica), metonimias (propiedad indicial) o símbolos (propiedad convencional) visuales y en algunos casos, representan en imagen expresiones metonímicas verbales: dibujar estrellas por la expresión "ver las estrellas" al recibir un golpe; un tronco y una sierra para indicar el sueño profundo y sonoro, evocando la expresión "dormir como un tronco"; el foco de luz para expresar la idea luminosa remitiendo a la expresión "prenderse la lamparita”; el corazón para simbolizar amor y un corazón roto para simbolizar desamor. Otros ideogramas son diversos signos gráficos que designan palabras soeces y signos de interrogación para indicar perplejidad (Gubern, 1974). Los ideogramas se caracterizan por ofrecer una economía en la representación, dado el alto grado de convencionalidad que poseen en el mundo del humor gráfico y la historieta, si bien varían en el estilo.

En la intersección indicial-convencional ubicamos a las líneas de movimiento, que son símbolos cinéticos (Gasca y Gubern, 1988) y contribuyen a la construcción de temporalidad en la narración. Representan diferentes tipos de movimientos, como trayectoria (identificada con una o más líneas que conforman una estela); impacto (suelen acompañarse por estrellas, pajaritos y/o nubes de polvareda); deformación cinética, producida cuando un objeto pierde su forma original a causa de la velocidad y resistencia que opera sobre el movimiento (McCloud, 1994; Segovia Aguilar, 2009); entre otros.

Del lado más netamente convencional ubicamos al cartucho, cartel, etiqueta, título y leyenda o final, manteniendo no obstante siempre presente la idea de continuidad. En estos recursos prevalece el carácter lingüístico y por lo tanto arbitrario, aunque como señalamos anteriormente, lo plástico puede aportar significativamente a la producción de sentido. El cartucho es una entidad separada del contenido de la viñeta que generalmente cuenta con un recuadro y se ubica en la parte superior de la misma (Saraceni, 2003). Se considera la más explícita forma de introducción de la voz del narrador (Postema, 2013) y su función es brindar información de tipo temporal, espacial o algún detalle referido a los personajes u objetos, aumentar el suspenso, presentar un nuevo episodio, etc. El cartel suele graficarse en escenarios en los que se representa la vía pública, ya sea fijo a un inmobiliario o en una manifestación, y presenta información variable, mientras que la etiqueta se utiliza para ayudar al lector a identificar un personaje, objeto o escenario. El título es el texto que se ubica generalmente en la parte superior de una viñeta, suele tener un tamaño y/o tipografía diferente al resto del texto. Se utiliza para atraer la atención de los lectores y suele presentar el tema de la viñeta o tira. La leyenda o final es un texto que se ubica generalmente en la parte inferior de la viñeta y al final en el caso de la tira y sirve para concluir una narrativa.

Hemos caracterizado estos recursos a partir de los usos más convencionales, aunque es necesario tener presente que la innovación interviene en grado variable, tanto en aspectos formales como funcionales. De ahora en adelante nos referiremos al conjunto de recursos (onomatopeyas, globos, ideogramas, líneas de movimiento, cartuchos, carteles, etiquetas, títulos y finales) como recursos específicos del género, teniendo en cuenta no obstante que son comunes al humor gráfico y la historieta. 
Por último, cabe señalar que en tanto lo plástico interviene en todos los recursos, optamos por graficarlo en la Figura 1 como una sombra que cubre todos los otros componentes.

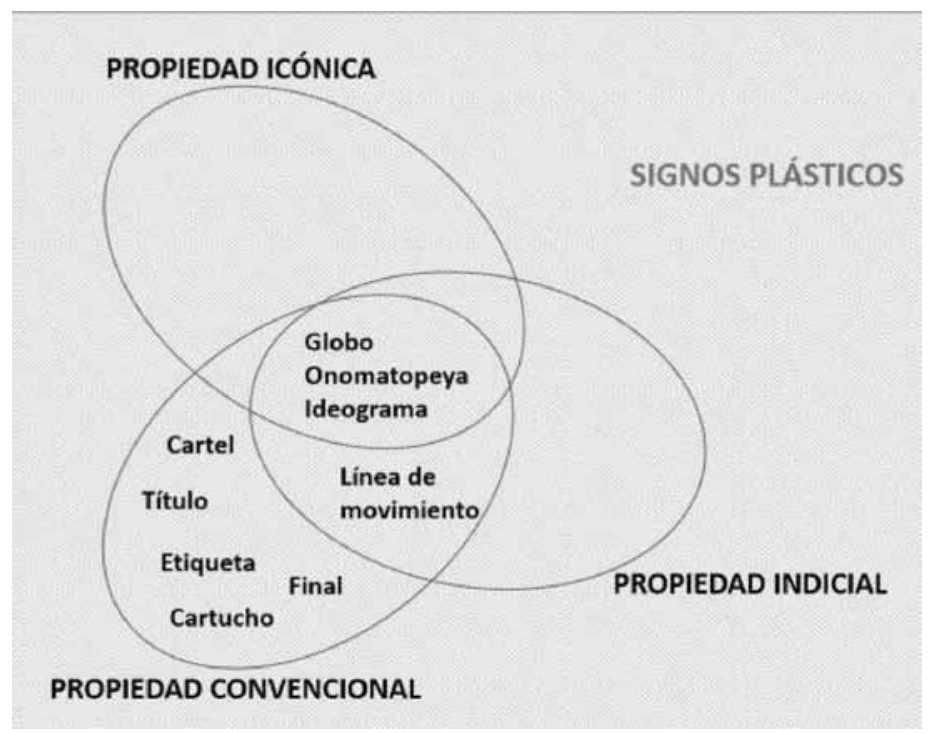

Figura 1. Propuesta de caracterización de los recursos específicos del género según las propiedades icónica, indicial y convencional peirceanas.

\section{Antecedentes de estudios en producción de historietas y humor gráfico}

Si los trabajos en torno a la interpretación de humor gráfico e historieta son relativamente numerosos, los de producción son bastante escasos y toman como objeto fundamentalmente a la historieta (e.g. Carl, 2010; Vento Escartí, 2012; Watkins, 2014).

Un estudio de referencia en contexto escolar es el de Teberosky, Portilla y Sepúlveda (2010), quienes realizaron una secuencia didáctica con alumnos de siete y ocho años en la que abordaron diversos recursos comunes a la historieta y el humor gráfico: globos de habla, grito, pensamiento o sueño, cartuchos, onomatopeyas y aspectos plásticos en la tipografía. En los textos producidos, los niños privilegiaron la puesta en escena de los personajes y utilizaron con más frecuencia los globos (de mayor a menor uso globos de habla, pensamiento o sueño y grito) y onomatopeyas. Enfatizaron la tipografía mediante el uso de mayúscula imprenta, grosor de la línea y color en globos de grito, onomatopeyas, títulos y la palabra fin al cierre de la historieta. Las autoras señalaron que si bien en general 
primó un uso convencional de los recursos, en ocasiones se evidenció desconocimiento o falta de sistematicidad.

En un estudio con escolares de entre diez y doce años, Segovia Aguilar (2009) solicitó la producción de una historieta de temática libre a partir de una plantilla de seis viñetas en la que se requería que incluyan cartuchos y globos de habla. Además de estos recursos, utilizaron en menor medida líneas de movimiento, ideogramas, onomatopeyas y globos de pensamiento. Focalizando en la construcción de la temporalidad en las historietas creadas por los niños, la tendencia generalizada fue incluir en la primera viñeta algunos globos de diálogo y la intervención del narrador mediante un cartucho, principalmente con alusiones temporales y en menor medida espaciales. Estos cartuchos buscaban cumplir una función de anclaje respecto a la imagen, aportando información aclaratoria, aunque en la mayoría de los casos fue redundante.

Encontró asimismo cuatro tipos de dificultades: en la destreza gráfica, dada por personajes faltos de movilidad y pobreza en detalles; en la construcción narrativa, dada por la exclusión de secuencias primordiales que producen grandes elipsis; en la escasa variedad de convenciones del género utilizadas, ya que se utilizaron principalmente cartuchos y globos y ocasionalmente otros recursos; y en menor medida en la expresión escrita, fundamentalmente en los diálogos, que aportaron expresiones sencillas, casi monólogos, de forma que los personajes aparecían en escena haciendo sólo acto de presencia, pero sin actuar.

\section{Nuestro estudio}

\section{Objetivos}

Sobre la base de la revisión presentada en apartados anteriores, con este estudio buscamos aportar al estudio empíricamente fundado de la multimodalidad y el humor en niños y adolescentes. Nuestro objetivo principal es identificar, describir y analizar diversas estrategias llevadas a cabo por niños y adolescentes para producir viñetas humorísticas multimodales inteligibles como así también dificultades sólo parcialmente superadas. En particular:

- Analizar las formas en que articulan el dibujo y la escritura para producir sentido y crear -con éxito variable- un efecto humorístico.

- Identificar, describir y analizar el repertorio de recursos específicos del género desplegados en las viñetas producidas, atendiendo a usos con mayor o menor grado de convencionalidad e innovación.

\section{Diseño y corpus}

Entre 2015 y 2017 diseñamos y dictamos ocho talleres de producción e interpretación de humor gráfico en la ciudad de San Carlos de Bariloche (Argentina). Se desarrollaron en 
contextos educativos formales (escuelas públicas y privadas) e informales (dos instituciones municipales: un Centro Integrador Comunitario y un Centro de Desarrollo de la Niñez y Adolescencia; y un Encuentro de Clubes de Ciencia organizado por el Ministerio de Ciencia y Tecnología de la Nación).

Siete de estos talleres consistieron en un único encuentro de dos horas de duración, en el que participaron entre 12 y 21 niños y adolescentes en cada oportunidad. El octavo se prolongó durante tres meses, alcanzando un total de 26 horas y contó con nueve participantes. El taller de un único encuentro fue pensado en tres etapas. En una primera instancia, se realizó en sesión plenaria un intercambio oral sobre qué es el humor gráfico, los formatos en que circula y la familiaridad de los participantes con el género. El intercambio continuó con la proyección de una presentación de aproximadamente 30 minutos, especialmente diseñada para el taller. En la misma se buscó abarcar, en los diferentes formatos (viñetas únicas y tiras humorísticas) y de forma progresiva, una amplia variedad de:

- Autores y estilos (autores profesionales de distintos países y autores niños y adolescentes participantes de talleres previos);

- Temas: desde temas lúdicos -metidas de pata, subversión del orden establecido, etc.hasta temáticas ubicadas bajo el término "humor serio" (Flores, 2000) -discriminación, violencia de género, contaminación ambiental, etc.;

- Recursos retóricos: hipérbole, personificación, metáfora, paradoja, alusión, ironía, metonimia, antítesis, inversión de roles, final inesperado, ironía del destino, etc.;

- Recursos plásticos: producciones en blanco y negro, en color, en lápiz, en tinta, con diferentes tipografías, ángulos de toma, planos, etc.;

- Recursos específicos del género: onomatopeyas, globos, ideogramas, líneas de movimiento, cartuchos, carteles, etiquetas, títulos y finales.

Durante la presentación se alentó la reflexión y participación de los niños y adolescentes, quienes intervinieron con entusiasmo, compromiso y evocando sus propias experiencias. Luego se destinó aproximadamente una hora a la producción individual de un texto humorístico. La consigna de producción fue libre, siendo la única restricción la articulación del dibujo y la escritura. Se ofrecieron hojas blancas, hojas borrador, reglas, lápices negros y de color, gomas, fibrines, fibras de color y crayones. La mayoría de los participantes se abocaron a la actividad con entusiasmo y concentración. Un grupo reducido encontró dificultades principalmente en la elección de la temática a tratar y/o en la forma de plasmarla gráficamente. Las encargadas del taller colaboraron con estas inquietudes, incentivando la recuperación de lo trabajado en la presentación, aclarando que no es necesario un manejo experto del dibujo para lograr una producción inteligible y humorística y recordando el carácter exploratorio de la actividad como oportunidad para crear un texto propio que verse sobre un tema que les resulte convocante.

Una vez que cada participante terminó su producción, se le solicitó que contase lo que había hecho y que explicase cómo se le había ocurrido. Esta entrevista individual tuvo una duración de tres a cinco minutos y brindó información que facilitó la interpretación de producciones poco o medianamente inteligibles, ya sea a nivel visual y/o verbal (identificación de personajes, objetos, situaciones, motivación de los autores, entre otros). 
Por su parte, el taller de larga duración se realizó en un Centro de Desarrollo de la Niñez y Adolescencia y consistió en encuentros semanales de dos horas cada uno. En cada encuentro también se proyectó una presentación inicial, en la cual se abordó algún contenido en profundidad: tipos de humor; formato (viñeta única y tira humorística); personajes (expresiones y gestos); escenarios; recursos retóricos; recursos plásticos; y recursos específicos del género. La consigna de producción varió en función del contenido trabajado en cada encuentro y siempre incluyó la articulación del dibujo y la escritura. Se buscó dinamismo en el diseño e implementación de las secuencias didácticas de cada encuentro, alternando intercambios en sesión plenaria con actividades de discusión en pequeños grupos. Algunas de estas actividades versaron sobre la interpretación de viñetas de actualidad elaboradas por profesionales, el análisis en cuanto a inteligibilidad y eficacia en la creación de efectos humorísticos de las viñetas creadas por los propios niños/as y adolescentes participantes, entre otras cuestiones.

En los ocho talleres participaron en total 109 niños/as y adolescentes (51 mujeres y 58 varones) de 10 a 19 años. El corpus que analizamos en este trabajo consta de 134 textos que articulan los modos visual y verbal. Cabe mencionar que hay textos en los que identificamos la producción de un/os efecto/s humorístico/s y otros en los que, si bien no se logra producir un efecto humorístico, se construye una trama valiéndose de diversos recursos específicos del género. Hemos excluido aquellos textos en los que sólo se pone en juego el modo visual, o los que pertenecen a otro género y no presentan recursos específicos, tal el caso de paisajes.

\section{Análisis}

Partiendo de las categorías mencionadas en apartados anteriores e introduciendo mínimos ajustes en función del corpus, cada texto fue codificado según la identificación de las siguientes dimensiones con sus respectivas categorías:

\section{Articulación verbal-visual:}

Convergencia: complementariedad; predominio verbal; predominio visual, lo verbal redunda parcialmente; predominio visual, lo verbal refuerza o amplía.

Divergencia: contradicción voluntaria, contradicción involuntaria.

Como puede apreciarse, las categorías son las mismas que las aplicadas en estudios anteriores (ver Pedrazzini y Scheuer, 2018b) con excepción de la contradicción involuntaria, que fue agregada para dar cuenta de casos en los que no existe la intencionalidad de contraponer modos con fines humorísticos.

\section{Recursos específicos del género:}

- Tipos: onomatopeyas, globos, ideogramas, líneas de movimiento, cartuchos, carteles, etiquetas, títulos y finales. 
- Cantidad total de recursos. Se contabilizan aquí todos los recursos identificados en cada producción.

- Cantidad de recursos específicos del género diferentes. Sólo se codifica, para cada producción, un recurso de cada tipo, aún si hay varios recursos de un mismo tipo. Por ejemplo, si se identificaron tres globos de habla y un ideograma esta dimensión se codifica con un dos. Sólo la primera de las dimensiones nominales presenta categorías mutuamente excluyentes, ya que en la segunda más de un recurso puede estar presente de forma simultánea en una misma producción. Cada autora codificó independientemente cada uno de los 134 textos multimodales y luego se contrastaron las codificaciones. Todas las discrepancias fueron resueltas mediante discusión.

\section{Resultados}

\section{Articulación verbal-visual}

En el $97 \%$ de los textos multimodales analizados se observa una relación de convergencia entre los modos verbal y visual (ver Figura 2): en el 66\% de los casos la articulación modal es de complementariedad, como en la Figura 3. Su autor se apoya en el potencial de cada modo semiótico y los pone en estrecha relación para construir la trama (volveremos sobre ésta más abajo). En 18\% de los casos, el modo verbal refuerza o amplía lo representado visualmente, como ocurre en la Figura 4, en la que el cartucho refuerza el sentido de ternura movilizado visualmente en la primera viñeta.

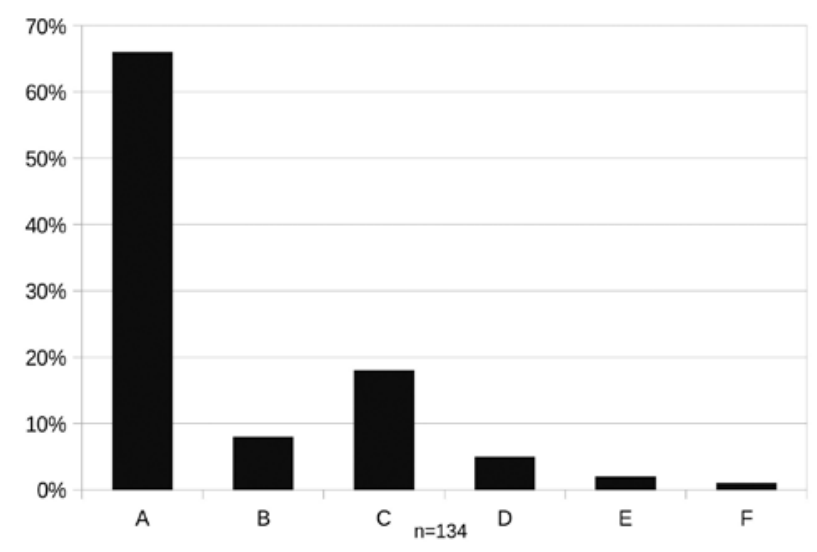

A: Complementariedad, B: Predominio verbal, C: Predominio visual - refuerzo verbal, D: Predominio visual - redundancia verbal, E: Contradicción voluntaria, F: Contradicción involuntaria.

Figura 2. Formas de articulación visual - verbal identificadas en el corpus analizado. 


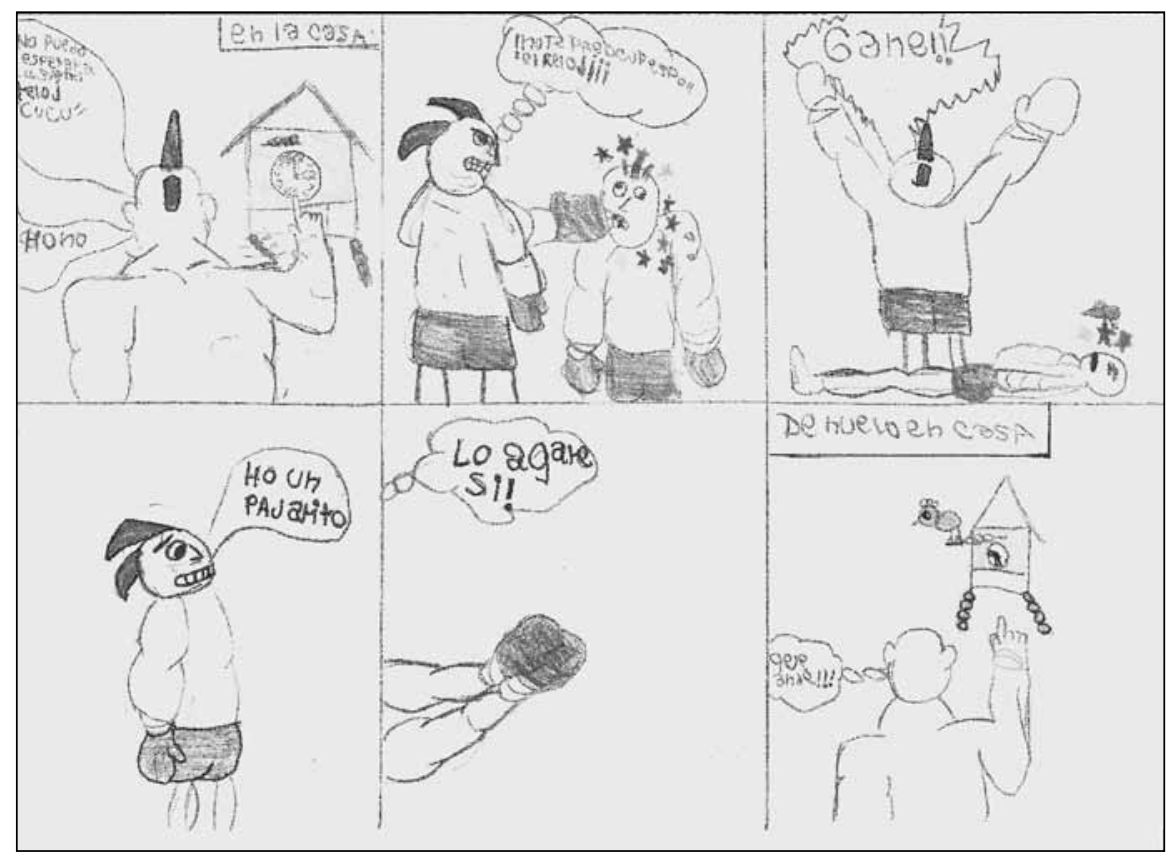

Figura 3. Lautaro, 11 años. Cartucho: En la casa. Globo 1: No puedo esperar a usar mi reloj “cucú”. Globo 2: ¡Oh, no! // Globo 3: iißNo te preocupes por el reloj!!! // Globo 4: ¡¡Gané!! // Globo 5: Oh, un pajarito. // Globo 7: Lo agarré, ¡si! // Cartucho: De nuevo en casa. Globo 8: ¡iiQue ande!!!

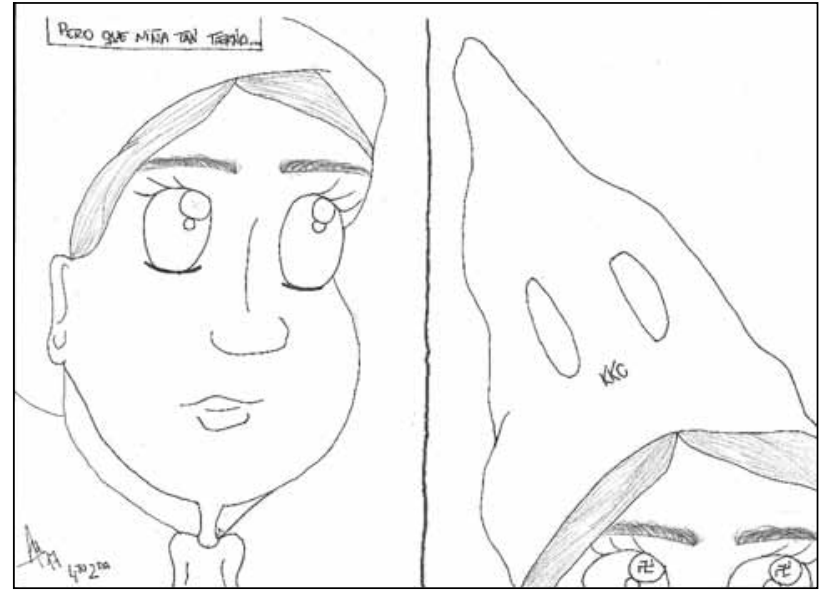

Figura 4. Ana, 17 años.

Cartucho: Pero qué niña tan tierna... 
En el $8 \%$ de los textos el modo visual ilustra lo verbal. En algunas pocas producciones (5\%), se observa una redundancia parcial a nivel intermodal. Un ejemplo de ello es la Figura 5, en la que los cartuchos intervienen como la voz del narrador -lo cual es acorde con su función convencional-, pero solapándose con lo ya representado de forma complementaria mediante el dibujo y uso de recursos específicos (globos, onomatopeya e ideograma de asombro). En la Figura 6, la etiqueta "Ideas" significa lo mismo que los ideogramas de foquitos. El globo recupera ese significado, tornando las etiquetas aún más redundantes. En sólo 3\% de los textos se observa una relación de divergencia entre los modos visual y verbal, correspondiendo el $2 \%$ a una contradicción voluntaria y el $1 \%$ restante a una contradicción involuntaria. Un ejemplo de contradicción involuntaria parcial es la Figura 7 , en la que la sonrisa de la mujer dibujada en la primera viñeta no se corresponde con lo que dice.

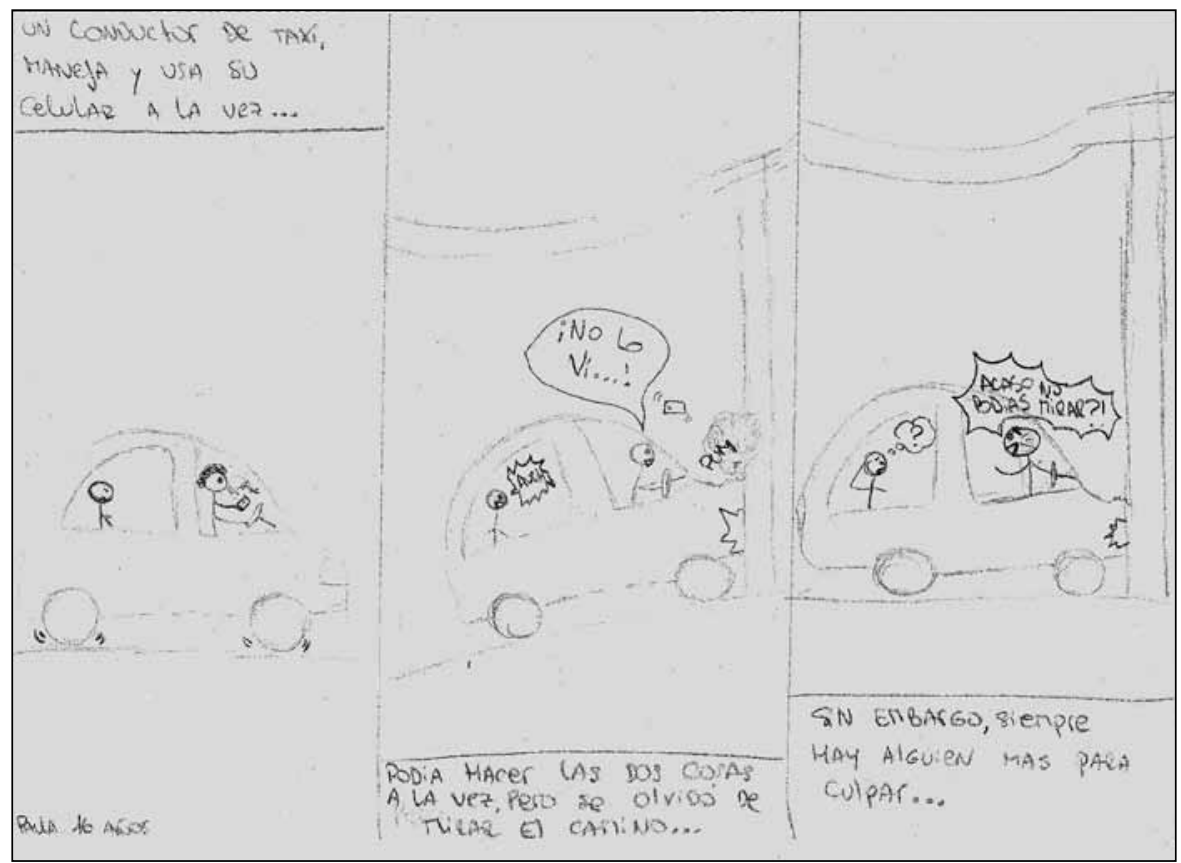

Figura 5. Paula, 16 años. Cartucho: Un conductor de taxi, maneja y usa su celular a la vez...

Onomatopeya: Tic Tic // Cartucho: Podía hacer las dos cosas a la vez, pero se olvidó de mirar el camino... Globo 1: ¡No lo vi...! Globo 2: Auch! Onomatopeya: PUM // Cartucho: Sin embargo, siempre hay alguien más para culpar... Globo 3: ¿Acaso no podías mirar? Globo 4: ? 

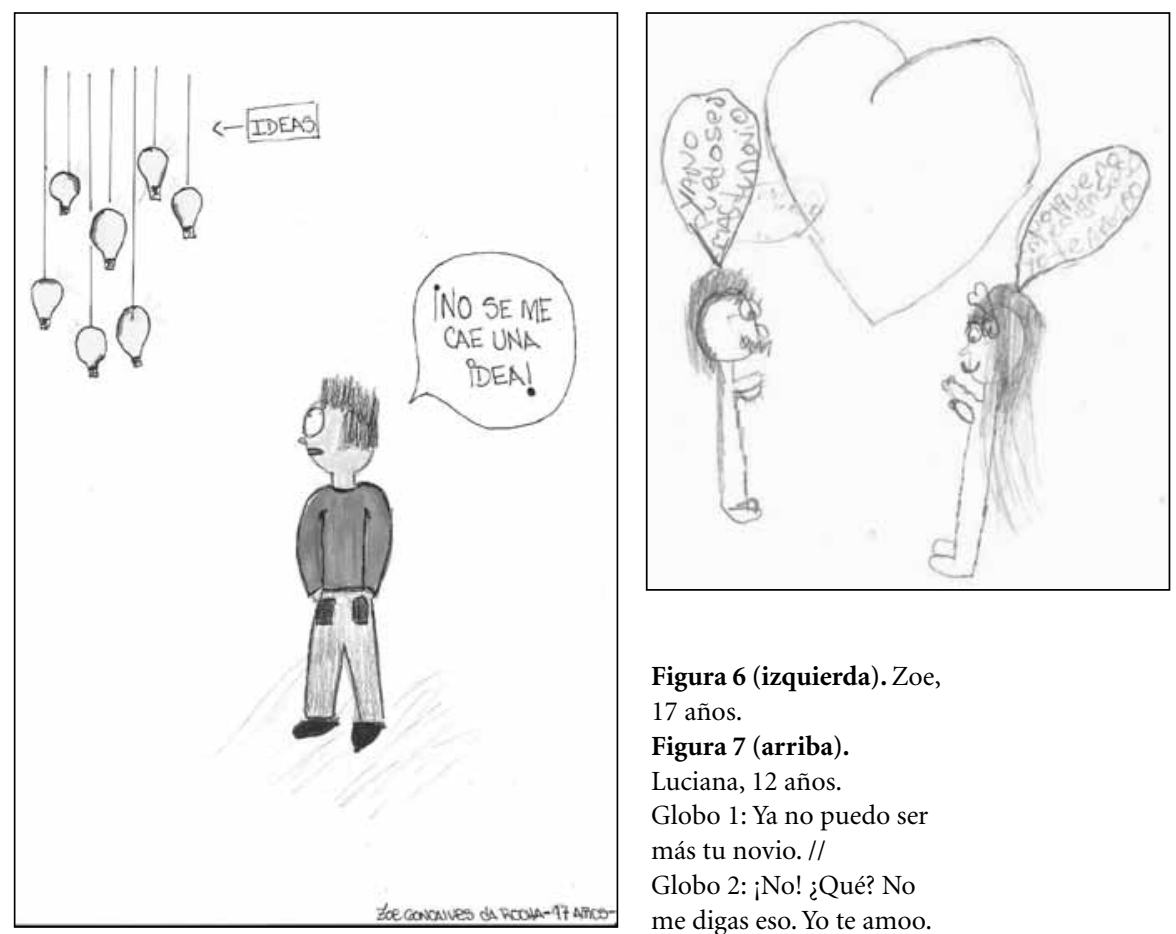

Figura 6 (izquierda). Zoe, 17 años.

Figura 7 (arriba).

Luciana, 12 años.

Globo 1: Ya no puedo ser más tu novio. //

Globo 2: ¡No! ¿Qué? No

me digas eso. Yo te amoo.

\section{Recursos específicos del género}

Se identificaron un total de 741 recursos específicos del género en los 134 textos multimodales. Si focalizamos en la cantidad de recursos diferentes por texto, la mayoría presenta dos recursos diferentes (40\%), seguido por un solo recurso (28\%), tres recursos (19\%) y cuatro o más recursos (13\%). El recurso que tiene un uso notablemente superior respecto a los otros es el globo de habla, contabilizado en 97 de los 134 textos (ver Figura 8). Siguen en frecuencia las líneas de movimiento (identificadas en 45 producciones), las etiquetas y carteles (detectadas en 41 producciones). Luego hay un uso muy parejo de ideogramas, cartuchos, globos de grito, globos de pensamiento o sueño y onomatopeyas (identificados en una veintena de producciones cada uno). El recurso menos utilizado es el título o final, contabilizado sólo en 7 producciones. 


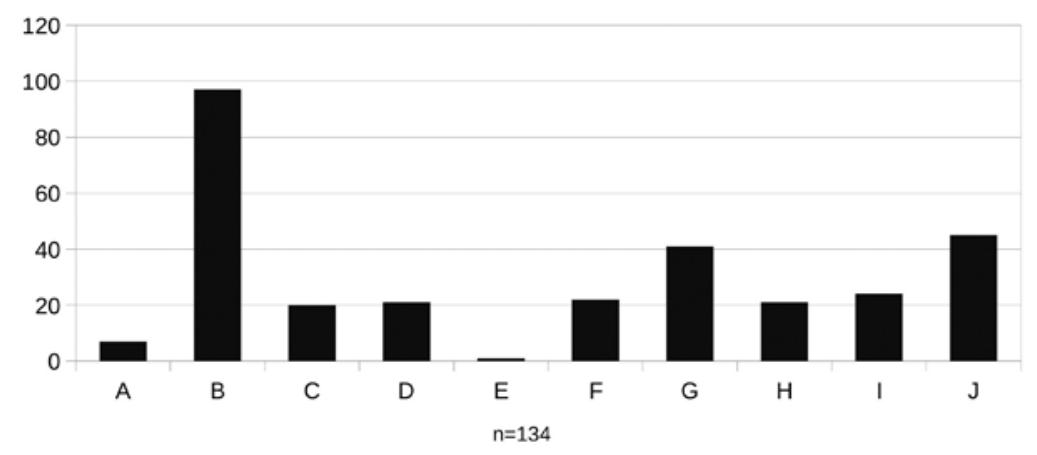

A: Título/ Final, B: Globo de habla, C: Globo de pensamiento/ sueño, D: Globo de grito, E: Globo de susurro, F: Cartucho, G: Etiqueta/Cartel, H: Onomatopeya, I: Ideogramas, J: Líneas de movimiento.

Figura 8. Recursos específicos del género identificados en el corpus analizado.

A continuación, nos aproximaremos al repertorio de recursos desplegados por los niños $\mathrm{y}$ adolescentes en sus producciones y analizaremos su uso, atendiendo a casos convencionales, a aquellos en los que se observan dificultades así como también a innovaciones que permiten, o bien sortear dichas dificultades con diversos grados de eficacia, o bien netamente construir el juego humorístico desde una mirada novedosa y ocurrente. Recuperando lo esbozado en la revisión teórica y de antecedentes y la Figura 1 propuesta, partiremos de los recursos que se encuentran en la intersección de las tres propiedades icónicas, indiciales y convencionales mencionadas, luego pasaremos a aquellos en intersección con propiedades indiciales y convencionales y finalizaremos con los casos en los que predomina la propiedad convencional.

Onomatopeyas: Los participantes utilizan una gran variedad de onomatopeyas y además las combinan con otros recursos, como por ejemplo globos de diálogo o grito. En este último caso, con la intención de enfatizar la intensidad del sonido. Otra forma en que logran representar dicha intensidad es mediante el uso de negrita y mayúsculas (ver Tabla 1). 


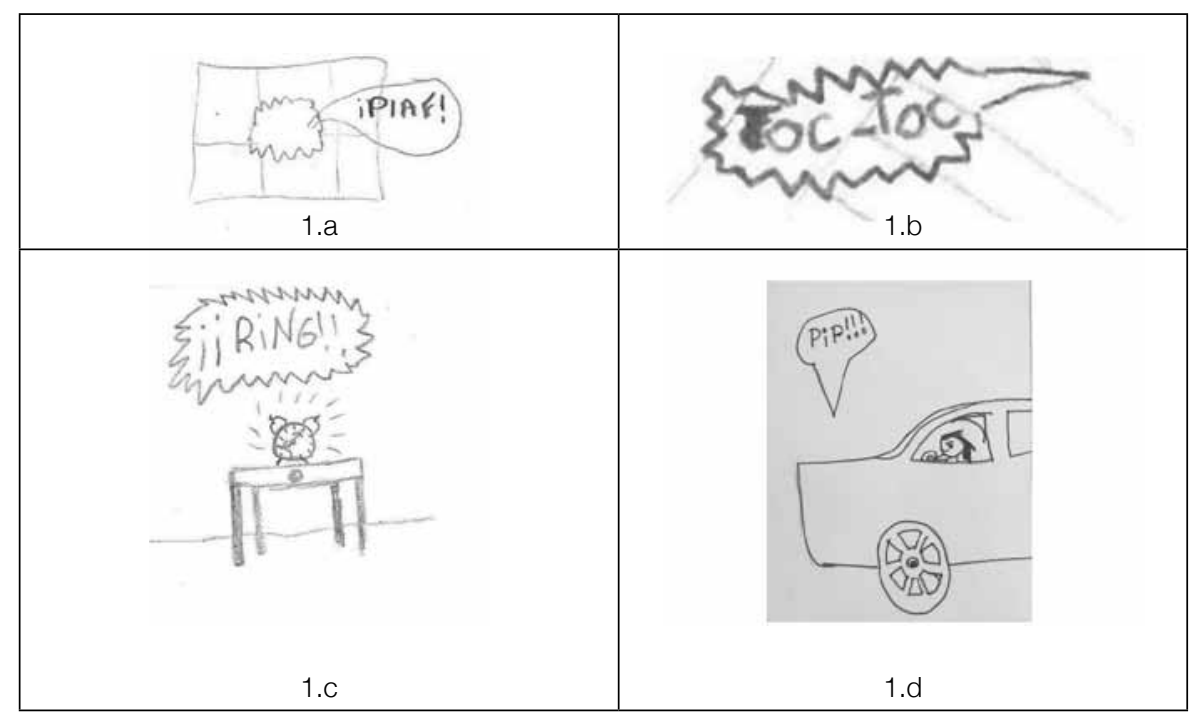

Tabla 1. Onomatopeyas

Globos: Si bien los globos de habla son los recursos gráficos más conocidos y utilizados en el género (McCloud, 1994; Saraceni, 2003) y también en nuestro corpus, no es la única forma de expresar el habla, ya que ésta puede estar escrita sin globo alguno. Esto se presentó sólo en un 3\% del corpus. El globo de nube es utilizado para indicar pensamiento, deseo y la acción de soñar (ver Tabla 2.a). Una sola producción contó con un globo de susurro (ver Tabla 2.b).

Entre las dificultades encontradas al emplear este recurso, encontramos que en $22 \%$ de las producciones existe cierta dificultad en la inclusión de texto escrito en el globo, siendo a veces demasiado texto para un globo pequeño (por ejemplo, Figura 7).

En menor medida (9\%), se utilizó un tipo de globo incorrecto o un globo híbrido (con características de dos tipos (ver ejemplo en Tabla 2.c), en la que el primer globo contiene la cola de un globo de habla, pero la forma de un globo de pensamiento). El caso de la confusión del tipo de globo refiere en su mayoría a la utilización de un globo de habla cuando el personaje está expresando un grito (por ejemplo, Tabla 2.d). En ocasiones los participantes encontraron la manera de comunicar el grito del personaje dentro de un globo de habla acudiendo al uso de mayúsculas, negrita y/o adicionando varios signos de exclamación (por ejemplo, ver Tabla 2.e). 


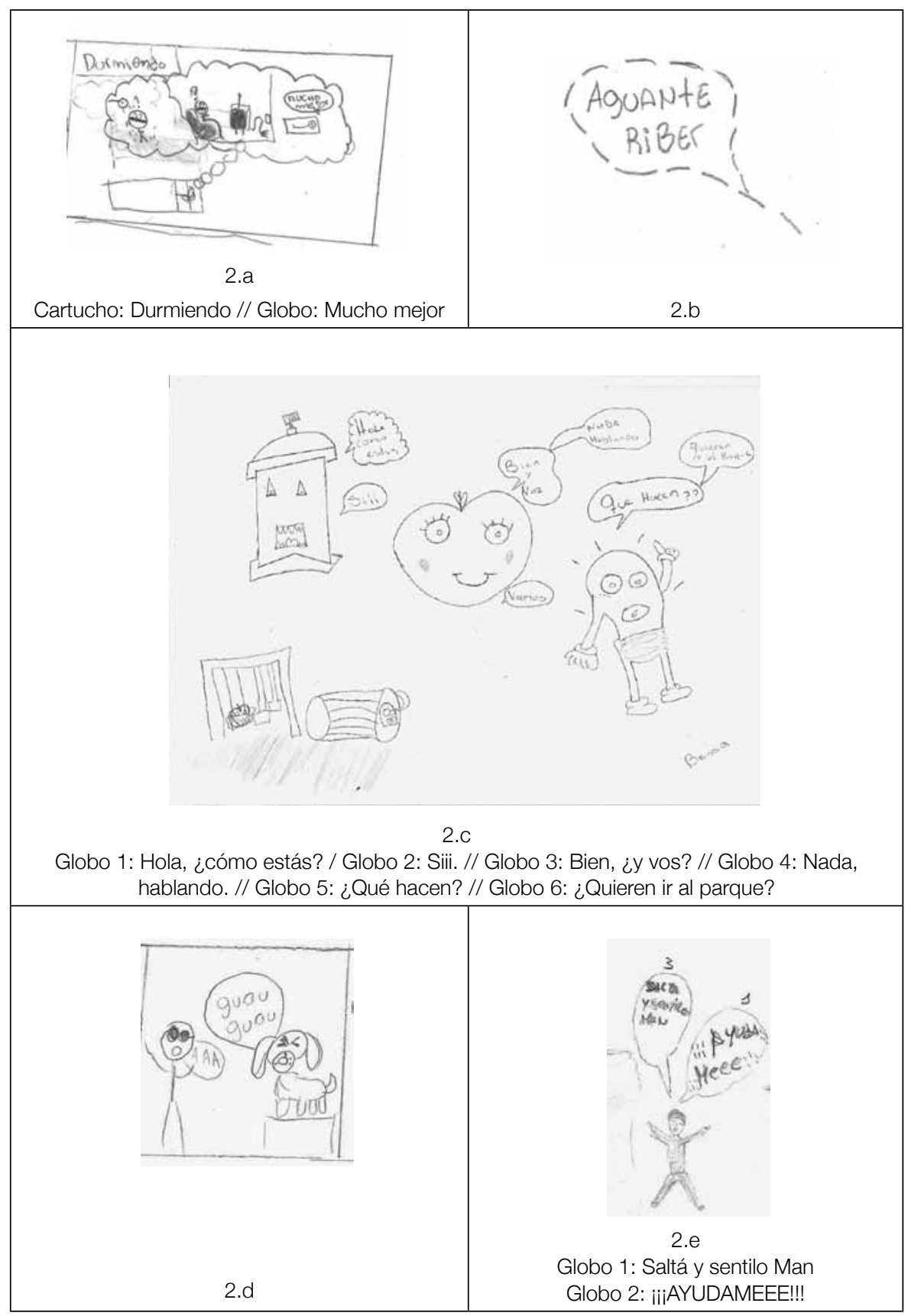

Tabla 2. Globos. 
Se observa también, aunque en pocos casos, una confusión entre globo de pensamiento y habla (por ejemplo, Tabla 2.f) aunque esta confusión es marginal respecto al empleo que los participantes hacen de ambos tipos de globo en la mayoría de los casos. Como puede observarse en la Tabla 2.g, los participantes lograron expresar eficazmente la diferencia entre el habla y el pensamiento acorde con la narrativa. Esto también se aprecia en la Figura 9 , en la cual el sentido humorístico reposa sobre el logro de esta diferencia.

Se observan también formas no convencionales en la utilización de globos. Por ejemplo, la utilización de flechas en lugar de las nubecitas para el globo de pensamiento (ver Tabla 2.h), y formas de escritura no convencional, como es el caso de la presencia de signos de admiración por fuera del globo (ver Tabla 2.i).

Una dificultad que obstaculiza la lectura fluida -si bien fue observada en un escaso número de producciones $(7 \%)$ - refiere a la incorrecta ubicación de personajes o globos (Tabla 2.c). Entre las formas de sortear esta situación, algunos participantes enumeraron los globos para guiar al lector (por ejemplo, Tabla 2.e), adoptando así otro modo semiótico para asegurar la inteligibilidad dentro de un uso poco convencional en el género.

En algunas pocas producciones se observa un relativamente alto grado de sofisticación en el uso de globos, por ejemplo en aquellos en los que no hay un personaje visible que los emita. Aquí identificamos tres casos diferentes: la puesta en escena de un personaje "tácito", desconocido, en tanto no se encuentra dibujado ni mencionado verbalmente pero que igualmente toma la palabra (por ejemplo el "público tácito" en el caso de la figura en la Tabla 2.i), la incorporación de un personaje al relato a través del habla que aparece dibujado posteriormente en la tira, y el dibujo parcial de un personaje, representando sólo una parte del cuerpo para dar cuenta del todo (sinécdoque) como una vía de focalizar la atención en una determinada acción (ver Figura 3) o emoción. 


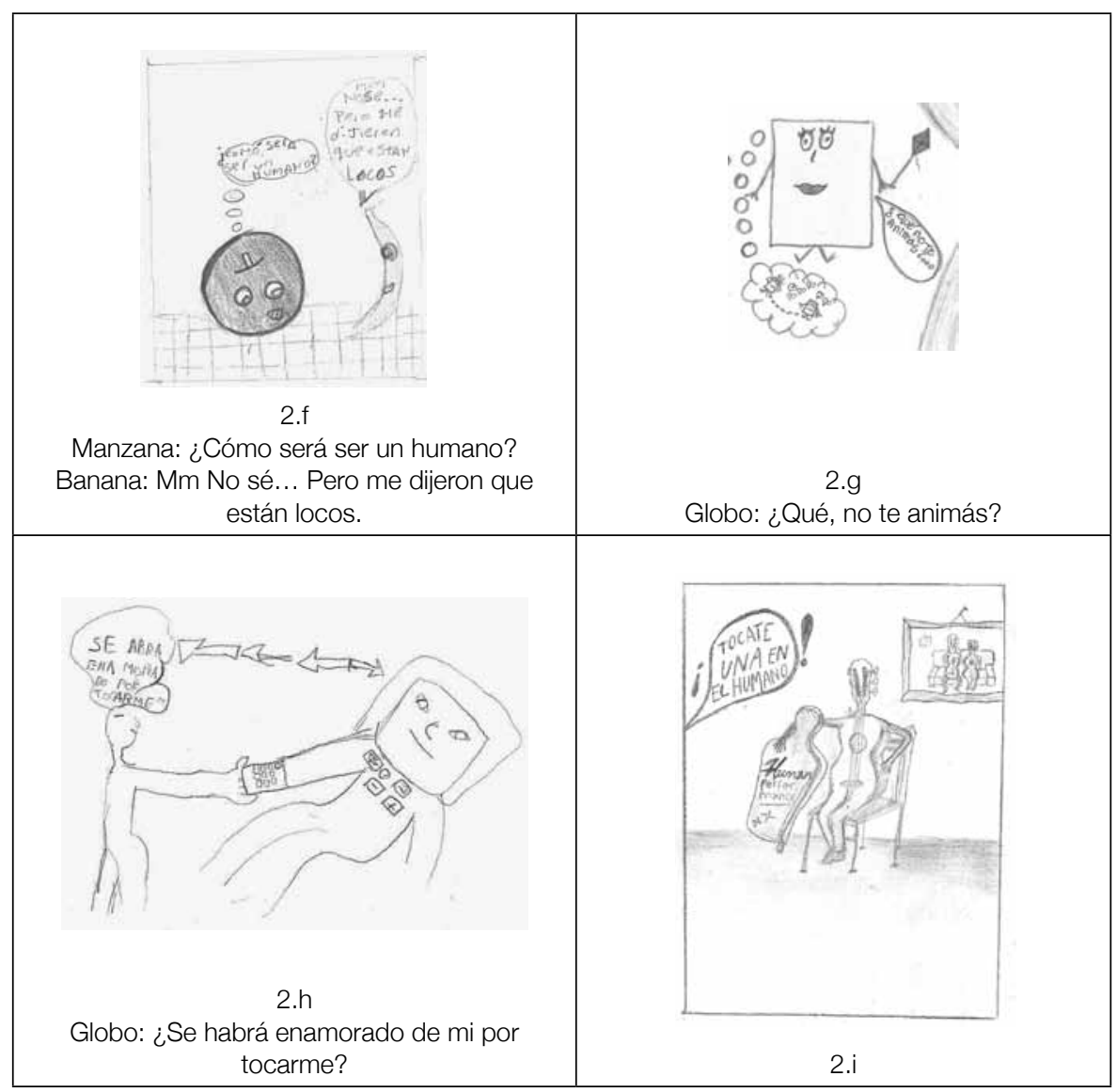

Tabla 2. Globos (continuación). 


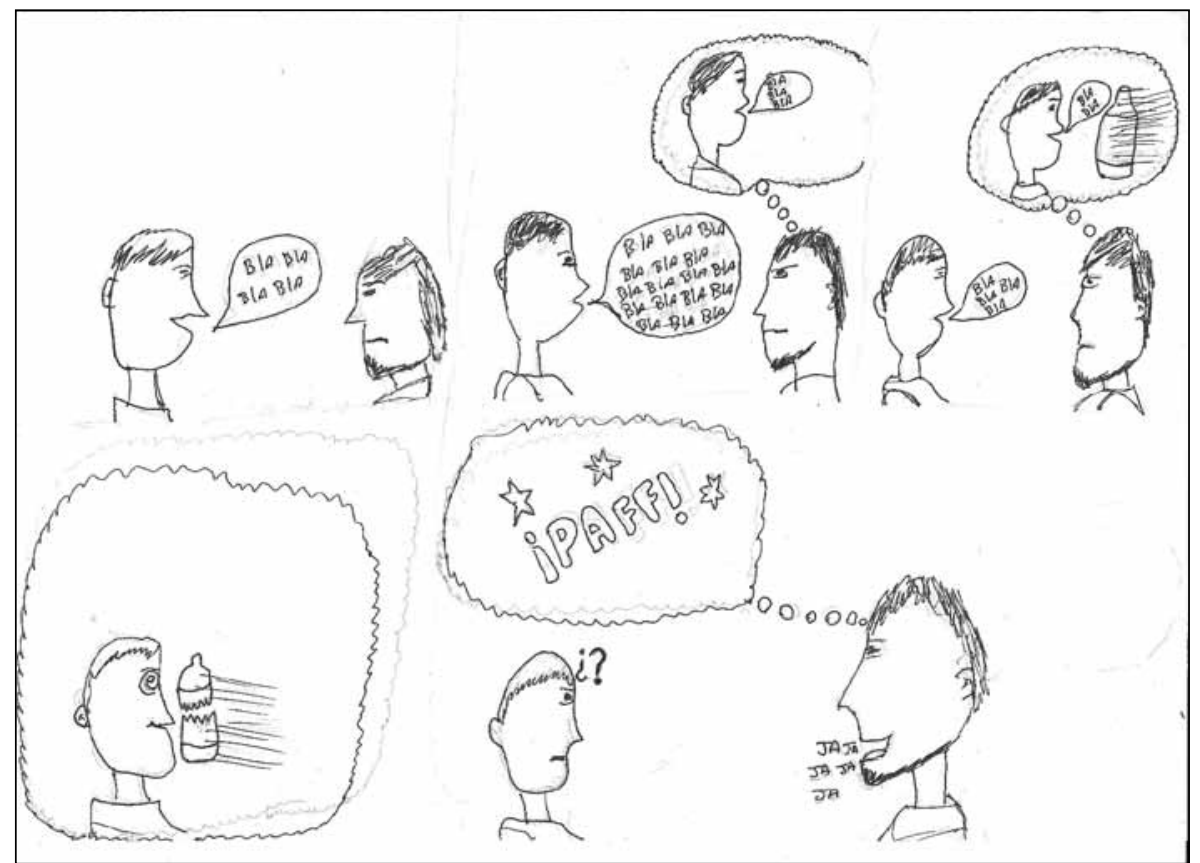

Figura 9. Samuel, 18 años. Globo 1: Bla, bla, bla, bla. // Globo 2: Bla, bla, bla, bla, bla... Globo 3: Bla, bla, bla. // Globo 4: Bla, bla, bla, bla. Globo 5: Bla, bla. // Globo: ¡PAFF! Habla sin globo: Ja, Ja, Ja, Ja.

Ideogramas: Entre el repertorio de ideogramas, se han representado en su mayoría corazones -fuera y dentro de globos- (ver Figura 7), signos de interrogación o exclamación para indicar perplejidad o asombro (ver Figuras 5 y 10), estrellas para indicar golpe (Figura 3) y símbolos para indicar insulto. Una producción que nos parece de particular interés es la Figura 3, en la que un ideograma convencional en el mundo del humor gráfico y la historieta, el pajarito para significar un fuerte golpe en la cabeza, se convierte en el objeto central de la trama. Al integrarlo en el relato, transforma este recurso en metalenguaje, aproximándose así al estilo contemporáneo de varios profesionales como es el caso de Liniers, quien a veces pone en escena y juega con la forma y el sentido de algunos recursos específicos del género. Otro ejemplo en el que un ideograma da cuenta de un juego a nivel de metalenguaje se observa en la viñeta de la Tabla 2.c, en el que un foquito de luz personificado tiene la idea de ir a jugar al parque. 


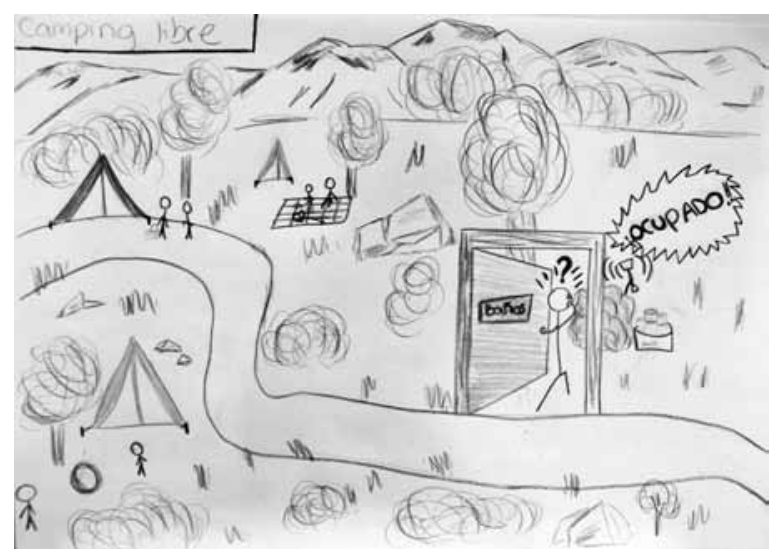

Figura 10. Iara, 14 años. Cartucho: Camping libre. Cartel: Baños. Globo: ¡Ocupado!

Líneas de movimiento: Son utilizadas principalmente para indicar desplazamiento (ver Figura 9), impacto (ver Figura 5), movimiento de diferentes partes del cuerpo o de objetos (ver Figura 10) y estados de asombro. En menor medida se han utilizado para graficar sonido (ver Tabla 1.c) y luz (foco en Tabla 2.c).

Carteles y etiquetas: Ambos recursos son utilizados acorde con sus funciones convencionales. Los carteles se usan para identificar o nombrar un lugar (Figura 10) o para presentar una toma de postura (Figura 11). Las etiquetas son empleadas para identificar un objeto o personaje (Tabla 2.i, Figura 6).

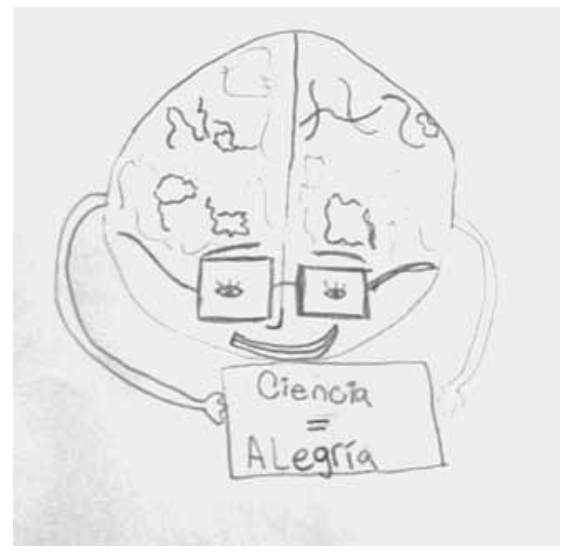

Figura 11. Federico, 15 años. 
Cartuchos: Suelen ser utilizados convencionalmente, tanto en lo que respecta a su función, brindando fundamentalmente información temporal y espacial, como en lo referente a su emplazamiento. Cuando presentan recuadro, su forma también es convencional, un rectángulo horizontal. En algunas ocasiones el recuadro no presenta línea en la parte superior. En sólo tres oportunidades, el cartucho deja de ser informativo para construir el juego humorístico, como es el caso de las Figuras 4 y 10. En la Figura 4, la autora juega con lo presentado multimodalmente en la primera viñeta para introducir un sentido opuesto en la segunda. En la Figura 10, la autora también construye el sentido humorístico a partir del contenido del cartucho "Camping libre" y el absurdo que se genera por estar el baño "ocupado".

Títulos y finales: La funcionalidad de ambos recursos está repartida principalmente entre aquellos que construyen el juego humorístico y aquellos que cumplen esta función y a la vez presentan información sobre el qué, cómo y dónde de la situación representada. En un único caso el final consistió en escribir la palabra "Fin", como cierre de una tira. En un sólo caso se identifican recursos plásticos en la escritura (tipografía y negrita) para colaborar en la construcción de sentido.

Además de los recursos específicos del género analizados, en los textos multimodales hemos identificado otros recursos que pertenecen a diferentes modos semióticos, tal es el caso de notas musicales y números que son usados para referir al sistema monetario, indicar peso, o bien para orientar la secuencia de lectura de globos o viñetas. También se observa el uso de flechas, que sirven para orientar o enfatizar la lectura de etiquetas o carteles, graficar la trayectoria de un personaje u objeto, indicar dirección o graficar una causa y su efecto. En ocasiones se dibuja más de una flecha, en lugar de una sola más grande o resaltada en color (ver Tabla 2.h).

Para finalizar, nos referiremos al uso de las viñetas en las tiras, específicamente, a la relación que los niños y adolescentes establecen entre las mismas por medio del uso de calles. En la gran mayoría de los casos, existe una clara separación entre viñetas, ya sea a través de líneas o espacios amplios. Sin embargo, en un $4 \%$ de las producciones se presentan dificultades en la inteligibilidad de la tira por la ausencia de calles (por ejemplo ver Tabla 2.c, en la cual es difícil comprender que el dibujo de la plaza corresponde a una segunda viñeta) o hipersegmentación de las mismas. Un ejemplo de esto último es la Figura 12, en la cual se sitúa en viñetas separadas a personajes que dialogan entre sí, por lo que se torna difícil seguir la secuencia. 


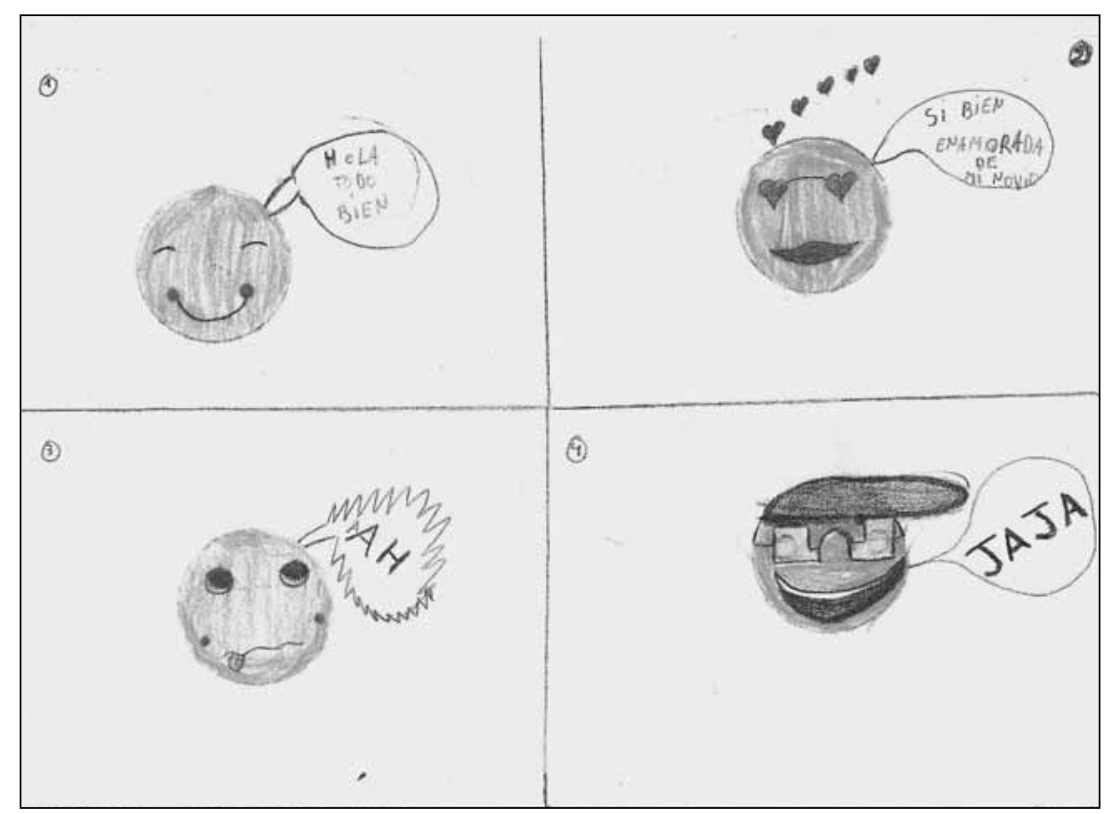

Figura 12. Tomás, 13 años. Globo 1: Hola, ¿Todo bien? // Globo 2: Si, bien, enamorada de mi novio. // Globo 3: ¡AH! // Globo 4: Ja, ja

\section{Conclusiones y discusión}

En este trabajo hemos brindado elementos que permiten pensar los numerosos recursos que operan en el humor gráfico desde una continuidad modal, proponiendo así una alternativa a la dicotomía ícono-lingüística vastamente extendida. En el humor gráfico operan diversidad de signos icónicos, plásticos, lingüísticos, y aunque con menor frecuencia también numéricos, musicales, entre otros, haciendo de este género un medio fecundo para estudiar la multimodalidad.

Hemos visto que la articulación del dibujo y la escritura para producir sentido y crear un efecto humorístico exige diversas habilidades que, al igual que autores como Pantaleo (2011) y Bateman (2014), creemos pueden ser desarrolladas y complejizadas mediante una formación explícita.

La mayoría de los textos multimodales analizados en este trabajo -ya sea viñetas únicas o tiras- ponen de manifiesto un esfuerzo por parte de los niños y adolescentes autores de sacar provecho de lo que cada modo semiótico puede aportar a los fines comunicativos en tanto es la relación de complementariedad la que prima. Los casos de redundancia intermodal-por definición siempre parcial-son escasos y los de contradicción involuntaria 
prácticamente inexistentes. La redundancia se observa al hacer uso de recursos como la etiqueta y el cartucho que en combinación con la imagen, resultan innecesarios. La redundancia al usar cartuchos también fue identificada en el estudio de Segovia Aguilar (2009), lo cual indicaría una dificultad adicional respecto a otros recursos por el hecho de introducir la voz del narrador de forma complementaria a la situación representada, en la que muchas veces los personajes mantienen un diálogo. En estos casos se introduce un juego polifónico que implica la capacidad de tomar distintas perspectivas de forma simultánea (Piaget, 1964). La contradicción involuntaria, distinta al uso deliberado de divergencia intermodal con fines humorísticos, se evidencia cuando la expresión facial de las emociones no es coherente con lo que el personaje expresa verbalmente.

El uso de recursos específicos del género es muy frecuente en el corpus analizado, con un promedio de cinco recursos y medio por texto, elevándose a tres de cada cuatro textos la combinación de al menos dos recursos diferentes. Hemos relevado algunas dificultades en su implementación, varias de las cuales remiten a los globos -el recurso más utilizado-, tales como la confusión entre tipos de globos, la inadecuada ubicación de personajes y globos, demasiado poco o mucho texto escrito en los mismos. En algunos casos, conscientes de la necesidad de asegurar una mayor inteligibilidad en sus producciones, los autores han acudido a recursos multimodales no necesariamente convencionales en el género, tal el caso de la enumeración de globos en un diálogo o de viñetas en una tira. Asimismo, hemos identificado la apropiación de recursos con un -en algunos casos- alto grado de sofisticación: construcción de la trama y del juego humorístico a partir de la utilización simultánea de globos de habla y pensamiento, representación parcial de un personaje para focalizar la atención, atribución de habla a personajes tácitos, entre otros. Además, esta sofisticación también se observa en la conjugación de diversos recursos plásticos en los dibujos como el uso de perspectiva o cambios en los ángulos de toma, en la tipografía, un manejo elíptico pero suficiente del texto escrito que permite introducir una ruptura con lo previsible, etc. Es interesante señalar que, en coincidencia con lo planteado por The New London Group (1996), Arizpe y Styles (2003), Pantaleo (2011, 2014), los intercambios que tuvieron lugar en sesión plenaria en los talleres a partir de los cuales se discutió en torno a diversos aspectos relacionados con los recursos del género y de forma más general en torno a la imagen y la escritura como modos semióticos, favorecieron el desarrollo de un metalenguaje entre los niños y adolescentes participantes. Cabe destacar el caso de unos pocos autores que además desplegaron habilidades gráficas de metalenguaje, lo cual se evidenció en particular en el uso de ideogramas y onomatopeyas.

Este trabajo constituye un punto de partida a tres futuras líneas de indagación. Una de ellas implica un estudio en profundidad de los desafíos cognitivos así como también de las estrategias desarrolladas para abordarlos a la hora de crear un efecto humorístico en las producciones. En segunda instancia, dado que hemos excluido el análisis exhaustivo de los componentes plásticos -que como vimos atraviesan todos los recursos-, sería interesante explorar cómo operan dichos componentes en cada recurso, atendiendo a las posibilidades de sentido que se despliegan. Una tercera línea de indagación refiere al estudio de los tipos y variedades en el uso de los recursos según el momento del desarrollo en el que se encuentra cada participante. 


\section{Agradecimientos}

Agradecemos a los niños/as y adolescentes participantes de los talleres, así como a los docentes y directivos involucrados.

Este proyecto ha sido parcialmente financiado con los proyectos de investigación: PIP CONICET 0129, PICT 2014-2929, PICT 2014-1607 y UNCO C-130.

\section{Notas}

1. Para favorecer la lectura se han introducido correcciones ortográficas. Las barras dobles indican cambio de viñeta.

\section{Referencias}

Arizpe, E. and Styles, M. (2003). Children reading pictures: Interpreting visual texts. London, UK: Routledge Falmer.

Attardo, S. (1994). Linguistic theories of humor. Berlín: Walter de Gruyter \& Co.

Avgerinou, M., y Ericson, J. (1997). 'A review of the concept of visual literacy', British Journal of Educational Technology, 28(4), 280-291.

Bateman, J. (2014). Text and Image: A Critical Introduction to the Visual/Verbal Divide. Nueva York: Routledge.

Bajtín, M. (2003). Estética de la creación verbal. México: Siglo XXI editores.

Bugallo, L., Zinkgräf, C. y Pedrazzini, A. (2018). El humor gráfico, una herramienta potente para enseñar y aprender. Contextos de Educación, 24, 55-65.

Calvas-Ojeda, M.G. y Espinoza Freire, E. (2017). La enseñanza de la historia a través de historietas, Maestro y sociedad, 14(4), 544-555.

Carl, A. (2010). Understanding and Creating Comics with Seventh Graders. BSides, University of Iowa Institutional Repository. Disponible en: https://ir.uiowa.edu/bsides/13

Cohn, N. (2013). Beyond speech balloons and thought bubbles: The integration of text and image. Semiotica, 197, p. 35-63.

Cruder, G. (2008). La educación de la mirada. Sobre los sentidos de la imagen en los libros de texto. Bs. As.: La Crujía.

Eisner, W. (1985). Comics \& Sequential Art. Florida, USA: Poorhouse Press.

El Refaie, E. (2013). Cross-modal resonances in creative multimodal metaphors. Breaking out of conceptual prisons. Review of Cognitive Linguistics, 11(2), 236-249.

Flores, A. B. (2000). "Humor y posmodernidad: el humor serio" En: La Argentina humorística. Cultura y discurso en los noventa. AAVV. Córdoba: Ferreyra editor.

Forceville, Ch. El Refaie, E. y Meesters, G., (2014). Stylistics and comics. En: Michael Burke (ed.), Routledge Handbook of Stylistics, pp. 485-499. London: Routledge

Fourastié. (1983). Le rire, suite. Paris: Denoël Gonthier.

Gasca, L. y Gubern, R. (1988). El discurso del cómic. Madrid, Cátedra.

Grupo Mu. (1992). Traité du Signe Visuel. Pour une rhétorique de l'image. París: Seuil. 
Gubern, R. (1972). El lenguaje de los comics. Barcelona: Ediciones Península. S.A.

Gubern, R. (1974). Mensajes icónicos en la cultura de masas. España: Lumen.

Joly, M. (2009). La imagen fija. Buenos Aires: La marca editora.

Kowalweski, H. (2015). From icono-linguistic unity to semiotic continuity. An alternative description of semiotic repertoire of comics. International Journal of Comic Art, 17 (1): 24-44.

Kress, G. (2010). Multimodality: A social semiotic approach to contemporary communication. Londres: Routledge.

Krusemark, R. (2016). Comic books in the American college classroom: a study of student critical thinking, Journal of Graphic Novels and Comics, 8:1, 59-78.

León Gómez, N. (2013). Creando, dibujando....aprendiendo matemática a través del comic, Memorias del I Congreso de Educación Matemática de América Central y El Caribe, República Dominicana, Nov. 2013. Disponible en Febrero de 2018 en: http://www. centroedumatematica.com/memorias-icemacyc/Minicurso,_Leon.pdf

Martinec, R. y Salway, A. (2005). A system for image-text relations in new (and old) media. Visual communication, 4(3), 337-371.

McCloud, S. (1994). Understanding comics. The Invisible Art. New York: Harper Perennial.

New London Group. (1996). A pedagogy of multiliteracies: Designing social futures. Harvard Educational Review, 66, 60-92.

Pantaleo, S. (2005). “Reading” Young Children's Visual Texts. Early Childhood Research \& Practice, 7(1), 1-14.

Pantaleo, S. (2011). Grade 7 students reading graphic novels: 'You need to do a lot of thinking. English in Education, 45(2), 113-131.

Pantaleo, S. (2014). Language, Literacy and Visual Texts. English in Education.

Pedrazzini, A. (2015). Las incoherencias insólita y paradójica en la caricatura política: juegos verbales y visuales en la ruptura de lo previsible. DeSignis, 22, 99-109.

Pedrazzini, A. y Scheuer, N. (2010). La interacción lingüística e ícono-plástica en la producción de caricaturas políticas: un estudio funcional y retórico. IRICE Nueva época, 21, 95-111.

Pedrazzini, A. y Scheuer, N. (2018a). Distinguishing cartoon subgenres based on a multicultural contemporary corpus. European Journal of Humour Research, 6(1), 100-123.

Pedrazzini, A. y Scheuer, N. (2018b). Sobre la relación verbal-visual en el humor gráfico y sus recursos. Cuadernos del Centro de Estudios en Diseño y Comunicación, 74, 123-141.

Peirce, C. S. (1998). The Essential Peirce. Selected Philosophical Writings. Vol. 2. Bloomington and Indianapolis: Indiana University Press.

Piaget, J. (1964/1991). Seis estudios de psicología. España: Labor.

Postema, B. (2013). Narrative Structure in Comics: Making Sense of Fragments. Rochester: RIT Press.

Samson, A. and Huber, O. (2007). The interaction of cartoonist's gender and formal features of cartoons. Humor. International Journal of Humor Research, 20, 1-25.

Saraceni, M. (2003). The language of comics. London: Routledge.

Segovia Aguilar, B. (2009). Análisis de las construcciones narrativas del espacio y del tiempo en los cómics de los escolares de Tercer Ciclo de la Enseñanza Primaria. Tesis Doctoral. España: Servicio de Publicaciones de la Universidad de Córdoba. 
Steimberg, O. (1998). Semiótica de los medios masivos. El pasaje a los medios de los géneros populares. Buenos Aires: Atuel.

Teberosky, A., Portilla, C. y Sepúlveda, A. (2010). Las convenciones del cómic para representar el discurso narrativo. IRICE Nueva época, 21, 45-63.

Tsakona, V. (2009). Language and image interaction in cartoons: Towards a multimodal theory of humor. Journal of Pragmatics, 41, 1171-1188.

Unsworth, L., Thomas, A., Simpson, A., and Asha, J. (2005). Children's literature and computer based teaching. Berkshire, UK: Open University Press. based teaching. Berkshire, UK: Open University Press.

Vento Escartí, M. (2012). Taller de cómic: creando historietas en un aula de primaria. Aula de innovación educativa. 208, 53-56.

Viau, J. Szigety, E. y Tintori, M.A. (2015). La utilización del comics como recurso didáctico para favorecer la apropiación de contenidos físicos, Revista de Enseñanza de la Física, 27, 587-592.

Vilches, L. (1984). La lectura de la imagen. Prensa, cine, televisión. Barcelona: Paidós.

Wallner, L. (2016). Speak of the Bubble. Constructing Comic Book Bubbles as Literary Devices in a Primary School Classroom. Journal of Graphic Novels and Comics, 8(2), 173-192.

Watkins, R. D. (2014). Sequential rhetoric: Teaching comics as visual rhetoric. Graduate Theses and Dissertations. 13940. USA: Iowa State University.

Yannicopoulou, A. (2004). Visual Aspects of Written Texts: Preschoolers View Comics. L1 - Educational Studies in Language and Literature, 4, 169-181.

Abstract: This work aims at the contribution of the empirically founded study of multimodality and humor in children and adolescents. It focuses on the creation of cartoons as a multimodal type of discourse, in which various signs - mostly iconic, plastic and linguistic- interact to make meaning and to create a humorous effect. Based on a corpus of 134 cartoons produced by children and adolescents between 10 and 19 years old, we analyzed the ways in which drawing and writing are combined, and we found that the complementarity relation between them is the primary one. This reveals the effort that is put into by the participants to take advantage of the potential of each semiotic mode. We also identified a repertoire of graphic resources deployed (speech balloons, motion lines, captions and labels, as the ones that appear the most), with different degrees of convention and innovation in the use of these resources. In addition, we described a series of strategies that are put into play to produce legible cartoons, while revealing difficulties that are only partially surpassed.

Keywords: cartoon - multimodal articulation - graphic resources - image.

Resumo: Este trabalho procura contribuir para o estudo empírico da multimodalidade e do humor em crianças e adolescentes. Concentra-se na produção de humor gráfico como um discurso multimodal, no qual diversos signos -principalmente icônicos, plásticos e 
lingüísticos- interagem para produzir significado e criar um efeito humorístico. Tomando como corpus 134 vinhetas humorísticas produzidas por meninas / meninos e adolescentes com idades entre 10 a 19 anos, analisamos as maneiras em que desenho e escrita são postas em relação e descobriu que a complementaridade é o prémio, que realiza um esforço para capitalizar o potencial de cada modo semiótico. Nós também identificar o repertório de recursos gráficos implantadas (com balões, movendo linhas, rótulos e cartazes como os mais numerosos), com base em aplicações com diferentes graus de convencionalidade e inovação e descrever várias estratégias implementadas para produzir vinhetas inteligíveis, aliviando também dificuldades apenas parcialmente superadas.

Palabras chave: Humor - articulação multimodal - recursos gráficos - imagem.

[Las traducciones de los abstracts fueron supervisadas por el autor de cada artículo] 